\title{
UPON SCHEDULING PROJECTS IN A DESIGN OFFICE
}

\section{Dimitri Golenko-Ginzburg1, Anna Baron², Avner Ben-Yair ${ }^{3}$ and Doron Greenberg ${ }^{4}$}

\author{
${ }^{1,2}$ Ben-Gurion University of the Negev, 84105 Beer-Sheva, Israel \\ ${ }^{3}$ Sami Shamoon College of Engineering, 84100 Beer-Sheva, Israel \\ ${ }^{4}$ Academic College of Judea and Samaria, 44837 Ariel, Israel \\ E-mail: ${ }^{1}$ dimitri@bgumail.bgu.ac.il;; ${ }^{2}$ malishev@bgumail.bgu.ac.il; ${ }^{3}$ avnerb@sce.ac.il; ${ }^{4}$ dorong@ti-israel.org
}

Received 10 May 2005; accepted 5 December 2005

\begin{abstract}
Several projects under random disturbances have to be realized in a project office within the planning horizon. The office comprises a number of different divisions, each of which carries out a certain stage of a project. Each project has its individual technological route and the chance contrraint to meet the due date on time. The problem is to determine starting time moments for each project to be passed on each division.
\end{abstract}

Keywords: project, scheduling, design office.

\section{Introduction}

It has been well-recognized in recent years that better scheduling may result in significant increase of average delivery performance in both projecting and manufacturing [1-6], especially for operations of random durations [716]. Practically in nearly all man-machine systems, including project offices, most of operations are of random duration. Due to random disturbances from the environment breakdowns of the equipment, a variety of random human factors affecting the work of personnel, etc., those operations have a random deviation from the average speed. Due to such random influences orders are often not manufactured and not delivered to the customers on time even using various scheduling techniques. Thus, the problem of increasing the orders delivery performance becomes very essential.

Most of the existing techniques for industrial scheduling is based on so-called priority rules [7-9, 17]. The objective is mostly to minimize the makespan (the schedule time) according to the starting time of operations obtained by using priority rules. It can be well recognized that one of the most fruitful approaches in industrial scheduling is the idea of pairwise comparison. The latter is usually used for choosing jobs (orders) for a processor from the line of jobs ready to be operated on that processor. If at a certain moment several jobs are waiting to be operated on a certain processor, pairwise comparison between the first two competitive jobs is arranged. The winner competes with the next job in the line, etc., until only one winner is left. The latter has to be chosen for the processor.

The idea of this section of the research is to expand this approach to the case of several projects with random time durations. The competition between two projects, which at a certain moment are seeking the same division, is based on comparing two different options:

Option A. The first project is chosen to be realized on the division and the second project will be realized when the first project is finished.

Option B. The second project is chosen for the division and the first one waits until the second project will be processed.

The idea of such comparison is to calculate for each alternative option the project delivery performance, i.e., the probabilities for both projects to meet their due dates on time. The option which ensures the maximal delivery performance for the couple of projects, i.e., for the project unification, has to be chosen. 


\section{The problem description}

A project office comprising $n$ simultaneously realized projects and $m$ divisions (laboratories, sections, departments, proving grounds, etc.) is considered. Each project consists of an individual chain of several stages, each of which needs to be realized during an uninterrupted period by a pregiven division. Each division can process at most one project at a time. A project cannot be realized at the same time by more than one division. Each stage of each project is carried out under random disturbances and, thus, has random duration. Due to the number of projects and the restricted division capacities, there may be projects which at a certain moment are waiting in a line ready to be realized by one and the same division. For each project its due date to be accomplished and delivered to the customer is pregiven.

The initial data for the $i$-th project, $1 \leq i \leq n$, is given in the form of a matrix row where each $\ell$-th element, $1 \leq \ell \leq m$, corresponds to the $\ell$-th stage $O_{i \ell}$ of that project and comprises three values: $\bar{t}_{i \ell}, \quad V_{i \ell}$ and $m_{i \ell}$. Here $\bar{t}_{i \ell}$ is the average value of random duration $t_{i \ell}$ of the project stage, $V_{i \ell}$ is the variance of $t_{i \ell}$ and $m_{i \ell}, 1 \leq m_{i \ell} \leq m$, is the ordinal number of the division which has to process stage $O_{i \ell}$. Thus, the system's initial data is given in the form of an $(n \cdot m)$ - matrix $W=\left\|\bar{t}_{i \ell}, \quad V_{i \ell}, \quad m_{i \ell}\right\|, \quad 1 \leq i \leq n$, $1 \leq \ell \leq m$, where each project has its individual route via the project office divisions. Note that if a project is structured from activities in the form of a network model, values $\bar{t}_{i \ell}$ and $V_{i \ell}$ can be determined beforehand by simulating the subnetwork which corresponds to stage $O_{i \ell}$. An essential number of simulation runs has to be carried out in order to obtain representative statistics to calculate $\bar{t}_{i \ell}$ and $V_{i \ell}$. If the project is not given in the form of a network model, values $\bar{t}_{i \ell}$ and $V_{i \ell}$ can be set by practitioners by using various expert methods, e. g. the Delphi method.

Several other essential terms are implemented in the model:

$S_{i \ell}$ - time moment stage $O_{i \ell}$ starts (a random variable conditioned on the model's decisions);

$F_{i \ell}$ - actual moment stage $O_{i \ell}$ is accomplished, $F_{i \ell}=S_{i \ell}+t_{i \ell}$ (a random variable);

$S_{i}=S_{i 1}$ - actual moment the $i$-th project starts (a random variable);

$F_{i}$ - actual moment for the $i$-th project to be accomplished (a random variable);

$E_{i}$ - earliest possible time moment to start realizing the $i$-th project (pregiven);
$D_{i}$ - due date for the $i$-th project to be accomplished (pregiven).

The problem under consideration centres on determining starting time values for each project to be passed on each division. Those values are not calculated beforehand and are random values conditioned on the model decisionmaking in the course of the project realization. The objective is to minimize the average value of the project makespan subject to the chance constraints.

The project management sets for each project two chance constraints: value $p^{*}$-the desired probability for the project to be accomplished on time, and $p^{* *}<p^{*}-$ the least permissible probability for the project to meet its due date on time.

Decision-making is carried out via pairwise comparison by examining the project delivery performance and it is used for choosing projects from a line.

\section{Optimization problem to minimize the project makespan}

The problem is to determine starting moments for each stage $S_{i \ell}, 1 \leq i \leq n, 1 \leq \ell \leq m$, to minimize the objective

$$
J=\operatorname{Min}_{S_{i \ell}}\left\{\operatorname{Max}_{i} F_{i}-\operatorname{Min}_{i} S_{i 1}\right\}
$$

subject to

$$
\begin{gathered}
S_{i 1} \geq E_{i} \\
\operatorname{Pr}\left\{F_{i} \leq D_{i}\right\} \geq p_{i}^{* *}, \quad 1 \leq i \leq n .
\end{gathered}
$$

The problem solution is based on the combination of a simulation model and a heuristic decision-making rule.

\section{The problem solution}

The basic idea of the heuristic solution is as follows. Decision-making, i.e., determining values $S_{i \ell}$, is carried out at moments $E_{i}$ and $E_{i \ell}$, when either one of the division is free for service or a certain stage $O_{i \ell}$ is ready to be processed. If stage $O_{i \ell}$ is ready to be processed on the $k$-th division (free for service) and there is no line for that division, the project is passed to the division. Otherwise, the competition is arranged based on the idea of pairwise comparison.

If, at a certain moment $t, q$ projects with ordinal numbers $i_{1}, i_{2}, \ldots, i_{q}$ are waiting in the line and are ready to be passed to the $k$-th division to realize the corresponding 
stages $O_{i_{1} \ell_{1}}, O_{i_{2} \ell_{2}}, \ldots, O_{i_{q} \ell_{q}}$, we suggest to calculate four values (see [3-4]):

1. Probability performance $p_{t i_{1}}=p_{1}(t)$ for the first project to be accomplished on time on condition that the project is chosen for the division at moment $t$.

2. Probability performance $p_{t i_{2}}=p_{2}(t)$ for the second project to be accomplished on time on condition that the project is passed to the division at moment $t$.

3. Probability performance $p_{t+\bar{t}_{i_{1} \ell_{1}}, i_{2}}=p_{3}(t)$ for the second project to be accomplished on time on condition that the first project is passed to the division first, i.e. at moment $t$, and later on, at the time moment $t+\bar{t}_{i_{1} \ell_{1}}$, the second project will start to be processed by the division.

4. Probability performance $p_{t+\bar{t}_{i_{2} \ell_{2}}, i_{1}}=p_{4}(t)$ for the first project to be accomplished on time on condition that the second project will be chosen first, at moment $t$, for the division, and later on, at moment $t+\bar{t}_{i_{2} \ell_{2}}$, the first project will be passed to the division.

Those four conditional probabilities are calculated as follows

$$
\begin{aligned}
& p_{1}(t)=\Phi\left\{\frac{D_{i_{1}}-t-\sum_{s=\ell_{1}}^{m_{i_{1}}}-\bar{t}_{i_{1} s}}{\sqrt{\sum_{s=\ell_{1}}^{m_{i_{1}}} V_{i_{1} s}}}\right\}, \\
& p_{2}(t)=\Phi\left\{\frac{D_{i_{2}}-t-\sum_{s=\ell_{2}}^{m_{i_{2}}} \overline{t_{i_{2}} s}}{\sqrt{\sum_{s=\ell_{2}}^{m_{i_{2}}} V_{i_{2} s}}}\right\}, \\
& p_{3}(t)=\Phi\left\{\frac{D_{i_{2}}-t-\bar{t}_{i_{1} \ell_{1}}-\sum_{s=\ell_{2}}^{m_{i_{2}}} \bar{t}_{i_{2} \ell_{2}}}{\sqrt{\sum_{s=\ell_{2}}^{m_{i_{2}}} V_{i_{2} s}}}\right\}, \\
& p_{4}(t)=\Phi\left\{\frac{D_{i_{1}}-t-t_{i_{2} \ell_{2}}-\sum_{s=\ell_{1}}^{m_{i_{1}}} t_{i_{1} s}}{\sqrt{\sum_{s=\ell_{1}}^{m_{i_{1}}} V_{i_{1} s}}}\right\},
\end{aligned}
$$

where $\Phi(x)=\frac{1}{\sqrt{2 \pi}} \int_{-\infty}^{x} e^{-\frac{t^{2}}{2}} d t$ is a standard normal distribution and stages $O_{i \ell}, O_{i, \ell+1}, \ldots, O_{i m_{i}}$ have not yet been operated at moment $t$. An assumption is introduced that those future stages will not wait in lines.

After calculating values $p_{1}(t), p_{2}(t), p_{3}(t)$ and $p_{4}(t)$, decision-making is carried out analysing them.

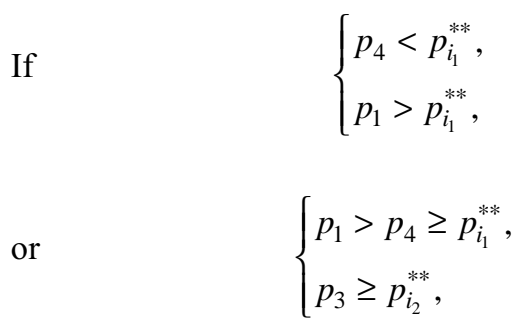

the $i_{1}$-th project wins the competition.

In cases $\quad\left\{\begin{array}{l}p_{3}<p_{i_{2}}^{* *}, \quad p_{2} \geq p_{i_{2}}^{* *}, \\ p_{1}>p_{i_{4}}^{* *} \geq p_{i_{1}}^{* *},\end{array}\right.$

or

$$
\left\{\begin{array}{l}
p_{1}>p_{4} \geq p_{i_{1}}^{*} \\
p_{i_{2}}^{*} \geq p_{2}
\end{array}\right.
$$

the $i_{2}$-th project is the winner. The winner competes with the $i_{3}$-th project, etc., until only one winner will be left. The latter has to be passed to be $k$-th division at moment $t$ for further realization.

Decision-making rules (8-11) have to be introduced at any essential moment, when a certain division is ready to realize a project and if there is a line of projects (i.e., more than one project) seeking for that division.

\section{Simulation model}

The suggested heuristic algorithm to solve the problem comprises simulation models together with corresponding decision-making rules. The simulation models:

- determine (within a routine simulation run) the system essential moments;

- determine the lists of projects which are waiting in lines;

- carry out decision-making to choose a project from the line;

- pass the project to the division in case if there is only one project seeking for that division;

- simulate the processing time $t_{i l}$ of stage $O_{i l}$ at moment $t$, when the project has been chosen for the di- 
vision; thus, the actual random moment $F_{i l}=t+t_{i l}$ to be accomplished is simulated as well;

- carry out a sample of simulation runs to obtain representative statistics.

\section{Numerical Example}

In order to evaluate the performance of the algorithm (4-11) an example has been chosen. Six simultaneously realized projects have to be processed on five different divisions. The initial data matrix is given in Table 1. The projects' parameters $D_{i}, p_{i}^{*}$ and $p_{i}^{* *}$ are presented in Table 2. For each project its delivery performance, i.e., the probability of meeting the due date on time, has been calculated on the basis of 500 simulation runs. The results are presented in Table 3. The following conclusions can be drawn from the Table:

1. An evident correlation between the projects' chance constraints and the corresponding delivery performance rates can be recognized. Lower $p_{i}^{*}$ and $p_{i}^{* *}$ correspond to lower delivery performance rates, and vice versa. This fully coincides with the general idea of the outlined problem.

Table 1. The initial data matrix (6 projects, 5 divisions)

\begin{tabular}{|c|c|c|c|c|c|}
\hline $\begin{array}{c}\text { Pro- } \\
\text { jects }\end{array}$ & Stage 1 & Stage 2 & Stage 3 & Stage 4 & Stage 5 \\
\hline 1 & $(150,100,1)$ & $(150,100,5)$ & $(120,100,4)$ & $(120,100,3)$ & $(120,150,2)$ \\
\hline 2 & $(160,900,1)$ & $(220,900,2)$ & $(480,900,3)$ & $(120,900,5)$ & $(130,400,4)$ \\
\hline 3 & $(120,90,5)$ & $(480,1600,2)$ & $(110,90,1)$ & $(130,400,3)$ & $(120,900,4)$ \\
\hline 4 & $(160,900,4)$ & $(120,900,3)$ & $(180,600,5)$ & $(160,100,2)$ & $(160,100,1)$ \\
\hline 5 & $(150,1000,5)$ & $(120,400,3)$ & $(120,900,2)$ & $(100,100,1)$ & $(130,500,4)$ \\
\hline 6 & $(450,1000,5)$ & $(140,900,4)$ & $(160,100,2)$ & $(160,400,3)$ & $(120,900,1)$ \\
\hline
\end{tabular}

Table 2. The projects' parameters

\begin{tabular}{|c|c|c|c|}
\hline $\begin{array}{c}\text { Projects } \\
i\end{array}$ & $\begin{array}{c}\text { Due date } \\
D_{i}\end{array}$ & $\begin{array}{c}\text { Chance } \\
\text { constraint } \\
p_{i}^{*}\end{array}$ & $\begin{array}{c}\text { Chance } \\
\text { constraint } \\
p_{i}^{* *}\end{array}$ \\
\hline 1 & 1200 & 0.90 & 0.75 \\
\hline 2 & 980 & 0.95 & 0.85 \\
\hline 3 & 1750 & 0.75 & 0.60 \\
\hline 4 & 1100 & 0.90 & 0.75 \\
\hline 5 & 1900 & 0.85 & 0.70 \\
\hline 6 & 1200 & 0.95 & 0.85 \\
\hline
\end{tabular}

Table 3. Delivery performance values

\begin{tabular}{|c|c|}
\hline Projects & Delivery performance values \\
\hline 1 & 0.785 \\
\hline 2 & 0.960 \\
\hline 3 & 0.642 \\
\hline 4 & 0.801 \\
\hline 5 & 0.725 \\
\hline 6 & 0.944 \\
\hline
\end{tabular}

2. The obtained delivery performance rates are reliable enough for practical industrial problems.

\section{Conclusions}

The following conclusions can be drawn from the study:

1. The developed model for scheduling the projects with operations of random duration to be processed by several divisions has been suggested. We applied the idea of pairwise comparison to choose the project to be operated by certain division. The objective is to minimize the average project makespan subject to the project chance constraints.

2. Future research has to be undertaken in order to develop a multilevel project management model which, besides stochastic network models, comprises other stochastic and deterministic models at different hierarchical levels.

\section{Acknowledgement}

This research has been partially suported by the Paul Ivanier Center on Robotics and Production Management, Ben-Gurion University of the Negev.

\section{References}

1. Barker, J. R. and Graham, B. M. Scheduling the general jobshop. Management Science, 31(5), 1985, p. 594-598.

2. Hunsucker, J. L. and Shah, J. R. Comparative performance analysis of priority rules in a constrained flow-shop with multiple processors environment. European Journal of Operational Research, 72, 1994, p. 102-114.

3. Industrial Scheduling (Muth, E. M. and Thompson, G. L. eds.). Prentice Hall, Englewood Cliffs, New Jersey, 1963. 493 p.

4. Sculli, D. Priority dispatching rules in an assembly shop. Omega, 15(1), 1987, p. 49-57.

5. Sen, T. and Gupta, S. A state-of-the-art survey of static scheduling research involving due dates. Omega, 12(1), 1984, p. 63-76.

6. Snyder, C. A.; Cox, J. F. and Clark, S. J. Computerized production scheduling and control systems: major problem areas, methods. Operations Research, 55, 1985, p. 319-328.

7. Gere, W. S. Heuristics in job-shop scheduling. Management Science, 13(3), 1966, p. 167-190.

8. Golenko-Ginzburg, D. and Kats, V. Priority rules in job-shop scheduling. In: Proceedings of the International Workshop "Intelligent Scheduling of Robots and Flexible Manufacturing Systems", Holon, July 2, Israel, 1995, CTEN Press.

9. Golenko-Ginzburg, D.; Kesler, S. and Landsman, Z. Industrial job-shop scheduling with random operations and different priorities. International Journal of Production Economics, 40, 1995, p. 185-195.

10. Gonik, A. Planning and controlling multilevel stochastic projects, Ph. D. Thesis, Ben-Gurion University of the Negev, Beer-Sheva, Israel, 1995. 95 p.

11. Grabowski, J. and Janiak, A. Job-shop scheduling with resource time models of operations. European Journal of Operational Research, 28, 1987, p. 58-73. 
12. Graves, S. C. A review of production scheduling. Operations Research, 29, 1981, p. 646-675.

13. Haupt, R. A survey of priority rule-based scheduling. $O R$ Spectrum, 11, 1989, p. 3-16.

14. Pinedo, M. Minimizing the expected makespan in stochastic flow shops. Operations Research, 30, 1982, p. 148-162.
15. Pinedo, M. Stochastic scheduling with release dates and due dates. Operations Research, 31, 1983, p. 559-572.

16. Pinedo, M. and Weiss, G. The largest variance first policy in some stochastic scheduling problems. Operations Research, 35, 1987, p. 884-891.

17. Panwalker, R. and Iskander, W. A survey of scheduling rules. Operations Research, 25(1), 1977, p. 45-59.

\section{PROJEKTU SUDARYMAS VEIKIANT ATSITIKTINIAMS TRIKDŽIAMS}

\section{Golenko-Ginzburg, A. Baron, A. Ben-Yair and D. Greenberg}

S a n tra k a

Straipsnyje nagrinėjama problema, kai įvairių atsitiktinių trikdžiu veikiama projektavimo organizacija per nustatytą laiką turi sudaryti kelis projektus. Projektavimo įmonè sudaryta iš daugelio skyrių, kurie kuria savo projekto etapą. Kiekvienas projektas turi individualų kūrimo eiliškumą ir laiką. Svarbiausia nustatyti laiko momentus, kada atskiros projekto dalys turi būti pristatytos atitinkamiems skyriams.

Raktažodžiai: projektas, grafiko sudarymas, projektavimo įmonè.

Dimitri GOLENKO-GINZBURG. Professor, D. Science, Ph.D, Department of Industrial Engineering and Management (Professor Emeritus), Ben-Gurion University of the Negev and Department of Industrial Engineering and Management, Academic College of Judea and Samaria. He was born in Moscow in 1932. He received his M.A. degree in Mathematics from the Moscow State University in 1958 and his Ph.D. degree in Applied Mathematics from the Moscow Physico-Technical Institute (Russia) in 1962. In Russia during the period $1958 \div 1985$ he wrote 14 books and more than 200 articles. His professional experience includes 45 years of scientific research and academic teaching in leading academic institutions in the former USSR and, after repatriating in 1985, in Israel. His current research interests are in managing and planning under uncertainty, planning and control of network projects, and industrial scheduling. During the period 1985 $\div 2004$ he published more than 150 articles. His recent publications have appeared in Mathematics and Computers in Simulation, International Journal of Production Economics, Automation and Remote Control, Communications in Dependability and Quality Management, and Computer Modelling and New Technologies.

Anna BARON. Ph.D, Department of Industrial Engineering and Management, Ben-Gurion University of the Negev. She earned her M.Sc. and Ph.D. in Economics in 1992 and 1999, respectively, from State Technical University of St.-Petersburg, Russia. After immigration to Israel she is a Doctoral Student in Department of Industrial Engineering and Management at the Ben-Gurion University of the Negev. Her present research interests are in the area of planning and control of network projects.

Avner BEN-YAIR. Ph.D, Department of Industrial Engineering and Management, Sami Shamoon College of Engineering. He was born in Moscow in 1961. He received his B.Sc. in Mechanical Engineering from the Moscow Polygraphic Institute, Russia, and his M.Sc. degree in Health and Safety Engineering and Management (Summa Cum Laude) from the Ben Gurion University of the Negev, Israel. He also received his Ph.D. degree in Industrial Engineering and Management from the Ben Gurion University of the Negev, Israel. His professional experience includes 13 years of engineering and management positions in Israeli chemical, pharmaceutical and high-tech industries. His current research interests are in economic aspects of safety, reliability and failure analysis, trade-off optimization models for organization systems, production planning, scheduling and control, cost optimization and PERT-COST models, and strategic management. He has published 25 articles in various scientific sources. His recent publications have appeared in Mathematics and Computers in Simulation, International Journal of Production Economics, Communications in Dependability and Quality Management, and Computer Modelling and New Technologies.

Doron GREENBERG. Ph.D, Department of Industrial Engineering and Management, Academic College of Judea and Samaria. He earned his doctoral degree in Economics from The University of Houston in 1992; his MBA specialized in Operation Management from the Recanati School of Management (1985); and his B.Sc. in Industrial Engineering from the Technion in Haifa (1980). He serves as a lecturer in the college of Judea and Samaria within the department of Economics and the department of IE. He also served as a lecturer in the Recanati School for management in The Tel Aviv University, in The Negev College on behalf of Pinchas Sapir, and in the Tel Aviv College of Engineering. 